Abstract P207 Table 1 Correlations between sleep-study measurements and clinical, demographic and anthropometric variables

\begin{tabular}{lllllllllll}
\hline & & & & \multicolumn{6}{c}{$\begin{array}{c}\text { Waist/ } \\
\text { Waist }\end{array}$} \\
& Age & Weight & BMI & Collar & Hip Circ. & Circ. & ratio & ESS & $\begin{array}{l}\text { STOP } \\
\text { BANG }\end{array}$ \\
\hline Total & $\mathrm{r}$ & 0.32 & 0.22 & 0.23 & 0.30 & 0.02 & 0.20 & 0.01 & -0.41 & 0.35 \\
$\mathrm{AHI}$ & $\mathrm{p}$ & $0.004^{*}$ & $0.02^{*}$ & 0.02 & 0.11 & 0.94 & 0.41 & 0.97 & 0.68 & $0.002^{*}$ \\
& $\mathrm{n}$ & 114 & 114 & 114 & 29 & 17 & 19 & 17 & 104 & 72 \\
$\mathrm{ODI}$ & $\mathrm{r}$ & 0.22 & 0.30 & 0.28 & 0.41 & 0.12 & 0.37 & 0.11 & 0.02 & 0.31 \\
& $\mathrm{p}$ & $0.02^{*}$ & $0.02^{*}$ & $0.003^{*}$ & $0.04^{*}$ & 0.66 & 0.12 & 0.68 & 087 & $0.01^{*}$ \\
& $\mathrm{n}$ & 106 & 106 & 106 & 27 & 17 & 19 & 17 & 97 & 67 \\
$\mathrm{Mean}^{2}$ & $\mathrm{r}$ & -0.36 & -0.24 & -0.24 & -0.46 & -0.11 & -0.18 & -0.02 & -0.10 & -0.297 \\
$\mathrm{SpO}_{2}$ & $\mathrm{p}$ & $<0.001^{*}$ & $0.01^{*}$ & $0.01^{*}$ & $0.02^{*}$ & 0.68 & 0.46 & 0.93 & 0.32 & $0.02^{*}$ \\
& $\mathrm{n}$ & 106 & 106 & 106 & 27 & 17 & 19 & 17 & 97 & 67 \\
\hline
\end{tabular}

${ }^{*}$ Denotes stastistical significiance at $\mathrm{p}<0.05$.

r, Spearman coefficient. Circ., circumference; ESS, Epworth Sleepiness Score; AHI, Apnoea Hypopnea Index; ODI, Oxygen Desaturation Index.

Conclusions Referral rates for sleep studies pre-bariatric surgery have risen exponentially over the past 20 months, and $37 \%$ of patients studied had at least moderate OSA, presenting a burden for sleep services and CPAP provision. $35 \%$ of patients studied had no evidence of OSA. Although a sensitive test, STOP BANG alone did not reliably identify these lower-risk patients.

\section{P208 A PROSPECTIVE OBSERVATIONAL STUDY TO EVALUATE THE EFFECT OF SOCIAL AND PERSONALITY FACTORS ON CPAP COMPLIANCE IN OSA}

doi:10.1136/thx.2010.151068.9

A Gulati, K Jordan, M Ali, R Chadwick, I E Smith. Papworth Hospital, Papworth Everard Cambridge, UK

Introduction Continuous positive airway pressure (CPAP) treatment for Obstructive sleep apnoea (OSA) is associated with variable initial acceptance and subsequent compliance with no consistent association with the severity of symptoms or physiological variables. There are very few data on the role of socioeconomic status, level of education and personality type. A recent retrospective study showed type $\mathrm{D}$ personality to be associated with poor compliance. ${ }^{1}$

Methods All patients with a confirmed diagnosis of OSA, recommended CPAP were considered. Baseline questionnaires were completed to assess employment and socio-economic status and type D personality. Compliance was measured at $6-10$ weeks and 6 months. Results 265 patients participated in the study. Seven switched to Bilevel PA, 2 were excluded and four withdrew their consent; 224 were still using CPAP at 6 months. At baseline mean age was 52.1 (SD 11.0)/y, M:F 205:60 (3.4:1), Epworth sleepiness score (ESS) 14 (SD 4.4), BMI 37.1 (SD 7.8), 4\% Desaturation index (DI) 27.9 (SD 20.6)/ $\mathrm{h}$ and AHI 28.0 (SD 18.6)/h. Mean compliance at 6-10 weeks and 6 months was 5.68 (SD 2.3) h and 5.31 (SD 2.3) h, respectively. $20.5 \%$ were using CPAP $<4 \mathrm{~h} /$ night at 6 weeks and $25.9 \%$ at 6 months. In comparison to individuals who were working (or retired from work), those who were long term unemployed $(n=17)$ had a lower average CPAP usage at $6-10$ weeks ( $4.08 \mathrm{~h}$; SD 2.3) and 6 months (3.2 h; SD 2.6). This group was also more likely to use CPAP $<4 \mathrm{~h} /$ night at $6-10$ weeks and 6 months (OR 5.06, $\mathrm{p}=0.001$ and $\mathrm{OR} 3.62, \mathrm{p}=0.01$ respectively). No association was found between different Socio-economic classes for people in work, type D personality, education level, sex, age, baseline ESS, DI and AHI with $6-10$ weeks or 6 month compliance. Compliance at 6-10 weeks correlated strongly with 6 months compliance ( $r s=0.82$ ).

Conclusion In our practice there is no significant association between CPAP compliance with socio-economic status, education level or the personality type. People who are long term unemployed may need more intensive support to get optimal benefit from CPAP

REFERENCE
1. Brostrom A. Journal of sleep research, Dec 2007.

\section{P209 WHAT MIGHT PATIENTS MEAN BY "SLEEPINESS"?}

doi:10.1136/thx.2010.151068.10

R Ghiassi, L O'Byrne, A R Cummin, M R Partridge. NHLI division, Imperial College, London, UK

Introduction Patients describe the symptoms of obstructive sleep apnoea syndrome (OSAS) in diverse ways. Clinicians and scientists may have difficulty in differentiating sleepiness from tiredness and tools to measure subjective or objective sleepiness do not always match clinician assessment of sleepiness. To better understand how patients' view 'sleepiness' we asked those under investigation for OSAS to describe in their own words what sleepiness means to them. Methods 24 patients (20 male and 4 female) participated in the study. ESS scores were recorded the morning after sleep study when patients were also asked to record in their own words what sleepiness means to them. Three independent scorers, (nurse, scientist and physician) and an independent academic referee, themed answers. Participants also underwent on Oxford Sleep Resistant Test (OSLER) to quantify objective daytime sleepiness as a comparator.

Results ESS scores were grouped into the following ranges: $\leq 10$, $11-15,16-24$ and mean OSLER scores calculated for each group, table 1. Individually, OSLER scores did not correlate well with ESS scores and there was great variability in levels of objective daytime sleepiness. On average each patient gave 6 descriptors relating to sleepiness. Descriptors of sleepiness fell into three main categories: mental function (eg, "mugginess"), physical sensation (eg, "even moving about is exhausting") and related to sleep or actual sleep (eg, "I always fall asleep in the cinema"). Patients with an ESS: $\leq 10$ gave more descriptors relating to physical sensations of sleepiness. Conversely patients with an $\mathrm{ESS} \geq 11$ gave more descriptors related to sleep or actual sleep.

\section{Abstract P209 Table 1}

\begin{tabular}{|c|c|c|c|c|c|c|c|c|c|}
\hline \multirow[b]{2}{*}{ ESS ranges } & \multirow[b]{2}{*}{$N(m: f)$} & \multirow{2}{*}{$\begin{array}{l}\text { Mean } \\
\text { ESS }\end{array}$} & \multirow[b]{2}{*}{ SD } & \multirow{2}{*}{$\begin{array}{l}\text { Median } \\
\text { OSLER }\end{array}$} & \multirow[b]{2}{*}{ SE } & \multirow[b]{2}{*}{ IOR } & \multicolumn{3}{|c|}{ No. sleepiness descriptors } \\
\hline & & & & & & & $\overline{\mathbf{M}}$ & $\mathbf{p}$ & $\mathbf{S}$ \\
\hline$\leq 10$ & $9(7: 2)$ & 8.9 & 1.0 & 22.5 & 4.7 & 23.2 & 7 & 23 & 9 \\
\hline $11-15$ & $7(5: 2)$ & 13.6 & 1.0 & 16.3 & 6.1 & 9.7 & 16 & 13 & 23 \\
\hline $16-24$ & $8(8: 0)$ & 18.5 & 2.1 & 17.6 & 6.2 & 15.1 & 10 & 12 & 22 \\
\hline
\end{tabular}

$\mathrm{M}$, mental function; $\mathrm{P}$, physical sensation; $\mathrm{S}$, related to sleep or actual sleep.

Conclusion This study has begun to assess how patients using their own words, describe the symptom of 'sleepiness'. Answers fell broadly into one of three categories: mental function, physical sensation and related to or actual sleep. Further understanding the construct of sleepiness to the patient may have importance in determining who is likely to benefit from therapy with CPAP.

\section{Developments in the delivery of lung cancer care P210 THE NATIONAL LUNG CANCER AUDIT-YEAR 5 COMPLETENESS AND OUTCOMES}

doi:10.1136/thx.2010.151068.11

${ }^{1} \mathrm{P}$ Beckett, ${ }^{1} \mathrm{I}$ Woolhouse, ${ }^{2} \mathrm{R}$ Stanley, ${ }^{1} \mathrm{M} \mathrm{D}$ Peake. ${ }^{1}$ Royal College of Physicians, London, UK; ${ }^{2}$ The Information Centre for Health and Social Care, Leeds, England

Introduction The National Lung Cancer Audit aims to record outcomes in lung cancer on a large scale and through case-mix 